\title{
The Dynamic Linkages among Sector Indices: The Case of the Egyptian Stock Market
}

\author{
Walid M. A. Ahmed ${ }^{1}$ \\ ${ }^{1}$ Faculty of Commerce, Ain Shams University, Cairo, Egypt \\ Correspondence: Walid M. A. Ahmed, Faculty of Commerce, Ain Shams University, P.O. Box 11566, Cairo, \\ Egypt. E-mail: walid_ahmed4@commerce.asu.edu.eg
}

Received: January 8, 2016

Accepted: February 9, 2016

Online Published: March 25, 2016

doi:10.5539/ijef.v8n4p23

URL: http://dx.doi.org/10.5539/ijef.v8n4p23

\begin{abstract}
The main thrust of this study is to investigate both the long-term and short-term links among sectors of the Egyptian equity market. The empirical analysis is carried out using Johansen's multivariate cointegration analysis and Granger's causality analysis. The investigation period extends from 3 April 2011 to 31 May 2015. The results of cointegration analysis indicate that there exists a single cointegrating vector within the sample sector indices. The Granger's causality analysis shows that the short-term causal relationships between the sector indices are substantially limited and, where they exist, practically unidirectional. By and large, an important implication of these findings is that there is still possibility to obtain gains from portfolio diversification in the short run. Nonetheless, investors with long-term horizon might not be able to benefit from diversifying into the various sectors of the Egyptian market.
\end{abstract}

Keywords: market sectors, Egypt, linkages, portfolio diversification, Johansen's cointegration technique, Granger's causality analysis

\section{Introduction}

In recent years, financial market integration has become a central theme in international finance literature, due to its important implications for many parties involved. One of the main motivations for exploring the integration of financial markets is to identify the size of potential gains arising from, and limitations of, international portfolio diversification.

Basically, incorporating foreign assets into a purely domestic portfolio gives an investor the opportunity to reduce portfolio risk as long as both foreign and local markets move arbitrarily away from each other. This stylized fact is much documented in past market integration literature (e.g., Grubel, 968; Levy \& Sarnat, 1970; Solnik, 1974; Lessard, 1976) that demonstrates that, as a result of the low level of associations between local stock market indices and their international counterparts, an investor would be able to decrease portfolio's total risk without undermining the portfolio's expected return by way of broadening his/her local portfolio to include foreign shares.

However, an important property associated with the global financial setting over the last four decades is the growing level of interrelationships amongst national markets due to a diversity of factors. In fact, the recent innovations in the field of financial products and services, the salient advances in communication and networking technologies, the removal of restrictions on foreign portfolio flows, the liberalization and deregulation of economies, and the upsurge in activities and transactions of multinational companies have strikingly strengthened the interdependence structure of world's capital markets, hence narrowing down the spectrum for international portfolio diversification.

Numerous empirical studies (e.g., Odier \& Solnik, 1993; Longin \& Solnik, 1995; Olienyk et al., 2002) lend support to this phenomenon, indicating that the remarkable increase in the comovement of national financial markets, as a consequence of globalization, leads to a considerable decrease in the gains derived for diversifying internationally. Additionally, the past three decades have been witness to a stream of terrible economic and financial crises, such as the 1987 Wall Street crash, the 1997 Asian crisis, the 2001 terrorist attack in the US, the 2007 subprime mortgage crisis that occurred in the US, and more recently the 2010 European sovereign debt crisis. Causing disruption to different markets of dissimilar sizes and structures across the globe, these financial 
woes and their spillover effects have strongly put the allure of international portfolio diversification in doubt.

In this context, an important strand of studies, looking at the dynamic linkages and the transmission of volatility amongst national capital markets, makes the point that the recent episodes of financial crises illustrate how closely the world's capital markets are connected and their roles in propagating a shock. The empirical results of these studies reveal substantial evidence for additional cross-border financial contagion provoked by these crises, implying that the efficacy of cross-border portfolio diversification typically tapers off at the time it is needed most (e.g., Arshanapalli \& Doukas, 1993; Sheng \& Tu, 2000; Izquierdo \& Lafuente, 2004; Bekeart et al., 2005). In line with this strand of literature, Mun (2005) argues that cross-market contagion could provide an adverse investment environment for risk managers and internationally diversified investors since the changing correlation pattern and financial disturbances make it more difficult for them to select an ex ante optimal investment strategy.

Additionally, there is growing evidence that the benefits of cross-border portfolio diversification strategy over those of diversification with domestic assets are statistically and economically insignificant. For example, Chang et al. (1995) and Errunza et al. (1999) demonstrate that the home-biased US investors may exhaust the benefits of cross-border diversification with portfolios constructed from equity assets traded on US stock exchanges. Cavaglia et al. (2000) show that since early 1997, opportunities for returns from sector tilts have dominated those emanating from countries' tilts and that this dominance has increased since 1997. Antoniou et al. (2010) find that it is possible for a British investor to exhaust the diversification gains of all foreign markets with UK-traded assets, a result challenging the view that cross-border equity acquisitions provide diversification benefits beyond those attainable by investing in assets within a country.

As pointed out by Ewing et al. (2003), financial market participants are interested not only in how individual stocks perform, but also in how different market indices perform. Indeed, many individual and institutional investors use sector indices as benchmarks to track the performance of publicly traded stocks and actively managed portfolios.

Taken together, the empirical evidence appears to support the argument that during times of global market volatility, diversification across sectors vis-à-vis across countries becomes paramount in order to accomplish the desired levels of investment risk and return.

With such backdrop, this study seeks to test for possible interdependences between the different sector indices in the Egyptian Stock Exchange (EGX, henceforth). More specifically, the following questions are empirically addressed:

- Does any long-run equilibrium relationship exist between the different sector indices of the EGX?

- Does the decision of diversifying domestically make sense for local investors?

- Does any short-run dynamic causal linkage exist between the different sector indices of the EGX? And which is the direction of causality, if any?

The investigation of this emerging market in particular is prompted by a couple of considerations. First, as the EGX currently functions in regulatory, institutional, cultural, and even psychological circumstances pretty dissimilar to those of its mature counterparts, a substantial amount of research is still needed to contribute to a better understanding of many issues relevant to the intersector linkages in this emerging economy. Second, unlike many mature and emerging stock markets, the EGX is characterized by its noticeable cross-sector and market capitalization differences that may eventually be more observable in empirical work.

The contribution of this study to the existing literature is three-fold: First, although a number of articles addressing the issue of market sector interrelationships and its practical implications for domestic diversification are available, articles focusing on the equity sectors of the EGX are virtually nonexistent, to the author's best knowledge. As such, this study makes the first attempt to provide empirical analyses about the long-run equilibrium relationships as well as the short-run dynamic linkages amongst the various sectors of the EGX. In this respect, some pertinent studies (e.g., Erb et al., 1997; Garten, 1997) point out that the evolution of an emerging market may be determined by characteristics that are unique to that particular country and the stage of economic development of the country. Therefore, it is important to analyze the behavior of an emerging market, such as the EGX, in isolation from its peers with a view to garnering information on the main characteristics of that market. Second, knowledge of the extent to which sector-specific stock market indices move together in a particular country is crucial to portfolio managers who try periodically to allocate efficiently the resources of investors. Specifically, investment portfolios based on economic sectors that are relatively independent are more likely to add value and increase the opportunity to eliminate a fundamental part of investment risk. Moreover, 
gaining a better grasp of the nature of the market sector interrelationships is of practical interest to a considerable number of international investors who wish to diversify across sectors and sectors. Third and last, the findings of this study could be of use to other emerging markets that have characteristics and circumstances similar to those of the EGX.

A couple of limitations of the current investigation must be highlighted. First, the study examines the stock index comovements amongst the sectors of the EGX, adopting an econometric perspective rather than an asset pricing model perspective. Second, issues such as the transmission mechanism of innovations and volatility shocks from one sector to the others are beyond the scope of this study.

Following this introduction, the study is structured in the following sequence. Section two presents a succinct review of the relevant literature. An overview of the EGX is provided in section three. Section four casts light on the different econometric methodologies applied in this study. Data description and preliminary analyses are presented in section five. Thereafter, an interpretation of the empirical findings and an analysis of their implications are presented in section six. Finally, section seven concludes.

\section{Prior Research}

There are substantial studies that explore the level of integration of the world's capital markets over time and across markets. These studies also investigate a diversity of issues germane to global market linkages, such as short-run and long-run interdependences of these markets (e.g., Chung \& Liu, 1994; Shamsuddin \& Kim, 2003; Phaylaktis \& Ravazzolo, 2005), leaders and followers amongst a set of financial markets (e.g., Arshanapalli \& Doukas, 1993; Ghosh et al., 1999; Masih \& Masih, 2002), and transmission mechanism of market volatility between countries (e.g., Soydemir, 2000; AuYong et al., 2004; Chung, 2005). A key contribution of this stream of research is the information it uncovers about the diversification potential amongst international capital markets.

However, a handful of studies have been undertaken to address the issue of sector index interrelationships concerning a particular economy. This is a persistent question for investors with preference for domestic equity and reluctance to diversifying internationally because the construction of a well-diversified asset portfolio relies on a sound understanding of how closely different market sector indices are interrelated and how these dynamic interrelationships vary over time.

A well-cited study in this line of research is that of Arbeláez et al. (2001) in which they investigate the short-run and long-run relationships amongst the several stock price indices of the Colombian capital markets. In addition to providing substantial evidence of long-run cointegration relationships, the empirical results reveal short-run dynamic linkages amongst the Colombian market sector indices in about $50 \%$ of the cases. Besides, these shortand long-run linkages have strengthened over time.

Ewing (2002) examines five major Standard \& Poor's stock indices (i.e., utilities, transportation, industrials, financials, and capital goods) in order to determine their interrelationships and how shocks to one index are transmitted to the others. By and large, the results of generalized variance decomposition analysis document strong interrelationships amongst the five Standard \& Poor's stock indices.

Exploring the dynamic relationships amongst major sector indices of the Chinese stock exchanges in Shanghai and Shenzhen, Wang et al. (2005) report evidence of a high degree of interdependence, implying that potential diversification benefits from sector-level investment may be relatively limited. They also find that Industry is the most influential sector in both exchanges, while Finance in Shenzhen offers the best diversification tool within the Chinese stock market.

Under a similar spirit, Mohamad et al. (2006) analyze the opportunity for diversification across different economic sectors for long-term investment using sector indices of the Malaysian Stock Exchange. The empirical results indicate high but unstable correlation relationships between different industry sectors in the Bursa Malaysia. This implies that investment managers should account for potential movements in sector-specific and sub-sector-specific risks. The results also imply that investment in one or two sectors of the stock market face higher total risk than in the past due to the increasing sector effects on portfolio investment.

Karmakar (2010) explores return and volatility transmission effects between large and small stocks in the national stock exchange in India employing daily index data on S\&P CNX Nifty, CNX Nifty Junior and CNX Midcap. The results show that there are very significant return spillovers from the market portfolio of large stocks to the portfolio of small stocks. Furthermore, consistent with the results of the studies for the US and other developed markets, the author finds that these return spillover effects are asymmetric in the Indian stock markets. 
Yunus (2013) assesses the dynamic interactions among the retail, office, industrial and residential property sectors of eight developed countries in North America and Europe. The results show that the four property sectors of the USA, Canada, Netherlands, and the UK appear to have full convergence, whereas those of Finland, France, Germany and Sweden have partial convergence. Furthermore, the residential sectors are the sources of the common stochastic trends that lead the remaining property types towards the long-run equilibrium relationships.

Arouri et al. (2014) look into the dynamic links between the US five-year financial credit default swaps (CDS) sector index spreads for the banking, financial services, and insurance sectors. They find that the CDS index spreads of the banking-financial services and banking-insurance sectors are governed by a cointegrating relationship. They also find evidence of significant short-term interactions between the CDS index spreads of these two sectors.

Loo et al. (2015) explore the long-run relationship and short-term linkage among the Asian real estate investment trusts (REIT) markets before, during and after global financial crisis of 2008. The Asian REIT markets are found to be cointegrated in the overall study period, crisis period and post-crisis period. Moreover, the number of causality relationships decrease over time. In the post-crisis period, the developed markets seem to have an influential role within the region.

Vardhan et al. (2015) examine the existence of both short-run and long-run relationships between the Indian major sector indices following the US sub-prime mortgage crisis of 2007. The results indicate that the eight sample indices share long-run equilibrium relationship. However, no short-run Granger Causality exists between sector indices during all sub-periods, which implies that there are diversification opportunities for development of short-term investment strategies in the Indian stock market.

\section{An Overview of the Egyptian Stock Exchange}

The EGX is one of the oldest stock markets set up in the Middle East. The EGX can be traced back to 1883 when the Alexandria Bourse was established, followed by the Cairo Stock Exchange in 1903 with 97 listed companies at an aggregate capital of L.E 29 million. Both Cairo and Alexandria Stock exchanges merged and managed to outperform throughout the 1940s and the early 1950s, to the extent that they ranked fifth among the world exchanges.

The Capital Market Authority (CMA) played an important role in sparking off and leading the effort for the revival of the EGX that seemed to be dormant from the sixties up to the eighties of the past century. In an attempt to create an enabling financial environment, the CMA implemented market-friendly reforms, including the harmonization of rules and regulations governing its domestic financial market, the creation of standards and benchmarks similar to those of international markets, and allowing the foreign participation. Currently, the EGX once again encompasses the two exchanges at Cairo and Alexandria, both of which are governed by the same regulatory agency, and share a common trading, clearing and settlement system.

The EGX 30, previously named CASE 30, is the main benchmark of the Egyptian Exchange. Retroactively computed as of January 2, 1998, the EGX 30 is comprised of the top 30 companies in terms of liquidity and activity. Additionally, the EGX launched a new index (EGX70) as of March 1, 2009, which measures the performance of the 70 most active companies in the Egyptian market, after excluding the 30 most active constituent-companies of EGX 30 Index. EGX 70 index keeps track of the change in the companies' closing prices, without being weighted by the market capitalization, and was retroactively computed as of January 1 , 2008.

In March 2010, the EGX launched a new index for listed companies called Standard and Poor's/Egypt Stock Exchange Economic Social and Governance Index (S\&P-EGX ESG). The new index aims to track the performance of the top 100 listed companies that demonstrate leadership on environmental, social and corporate governance issues.

According to the EGX Annual report (2014), the stock market recorded a total value traded of EGP291 billion in 2014, as opposed to EGP321 billion in 2010. The volume traded recorded about 57 billion securities in 2014 compared to 33.43 billion securities in 2010. Likewise, the number of transactions recorded 7.3 million transactions versus 10.2 million in 2010. The market capitalization of the listed stocks was EGP500 at the end of 2014, as compared to EGP488 billion at the end of 2010. The Egyptian Market showed a good performance during 2010, outperforming many Middle East stock indices, with EGX 30 and EGX70 surging by 32\% and 4\%, respectively, over the year. Moreover, EGX has been included in the Morgan Stanley Capital Index since 2001, and has shown the highest dollar growth in the category of "emerging markets Europe, Middle East and Africa" 
over the past years.

In January 2007, the EGX launched for the first time its sector indices, which comprise twelve indices tracking the price movements of the different sectors of the Egyptian market. These twelve sector indices include Banks, Basic Resources, Chemicals, Construction and Materials, Food and Beverage, Financial Services excluding Banks, Healthcare and Pharmaceuticals, Industrial Goods and Services and Automobiles, Personal and Household Products, Real Estate, Telecommunications, and Travel and Leisure.

Since January 2011, Egypt has seen a wave of tectonic socio-political events including, but not limited to, a popular uprising in 2011, presidential elections in 2012, a removal of a president from office in 2013, and another presidential elections in 2014. These political episodes have impacted upon the economic and financial climate. All stock market indices experienced steep declines. For instance, in the two consecutive trading days following 25 January 2011, nearly US $\$ 12$ billion of share values were quickly wiped out, making up $12 \%$ of the total market capitalization of the Egyptian market, which accordingly caused the main market indices EGX30, EGX70, and EGX100 to shed as much as $16 \%, 24 \%$, and $22 \%$, respectively, closing at all-time low levels of 5647,537 , and 885 points, respectively.

\section{Econometric Methodology}

This section sets out to outline the econometric methods adopted in this study, including unit root tests, Johansen's multivariate cointegration analysis, and Granger's causality analysis. These methods allow to look into the relationships among the different sectors of the EGX both in the short and long run.

\subsection{Tests of Nonstationarity}

An important condition for cointegration technique is to establish that the time series included in the cointegration model are integrated of the same order (Granger, 1986). Thus, the integration order of each series is examined using the Augmented Dickey-Fuller (ADF) test (Dickey \& Fuller, 1979, 1981), the Phillips-Perron (PP) non-parametric test (Phillips, 1987; Perron, 1988; Phillips \& Perron, 1988), along with the KPSS test (Kwaitkowski, Phillips, Schmidt, \& Shin, 1992).

The null hypothesis of both ADF and PP tests is that a series is nonstationary; hence, rejection of the unit root hypothesis is necessary to support stationarity. The asymptotic distribution of the PP $t$-statistic is the same as the ADF $t$-statistic. The main distinction between the ADF and PP tests lies in their treatment of any "nuisance" serial correlation. The PP test tends to be more robust to a wide range of serial correlations and time-dependent heteroskedasticity (Syriopoulos, 2004).

However, although the ADF and PP tests are commonly applied, some studies (Schwert, 2002; DeJong et al., 1992; Crowder, 1996) show that the ADF test notoriously lacks power against trend stationary alternatives, and that the PP test is not adequately informative in distinguishing between a unit root and a near unit root case, so these two tests may render spurious unit root results. These studies also imply that it would be an interest in unit root tests that have the null of no unit root. A popular test with this feature is the KPSS test of Kwaitkowski et al. (1992). In contrast to both ADF and PP tests in which the null hypothesis is nonstationarity, the KPSS test uses trend stationarity as the null hypothesis against the alternative of a unit root, so any lack of power will work in the opposite direction.

\subsection{Johansen's Cointegration Analysis}

The common purpose of cointegration analysis is to determine whether there exists a long-run equilibrium relationship amongst a set of nonstationary time series. According to this technique, two or more economic variables (i.e., stock market indices) are considered to be cointegrated if they exhibit a tendency to move together, at least in the long run. In the case of two nonstationary variables, an equilibrium relationship between $\boldsymbol{X}_{t}$ and $\boldsymbol{Y}_{t}$ implies that the two variables are cointegrated. If both $\boldsymbol{X}_{t}$ and $\boldsymbol{Y}_{t}$ are integrated of the same order $\boldsymbol{d}$ and there exists a linear combination of these series that is integrated of order $\boldsymbol{b}$ where $\boldsymbol{b}<\boldsymbol{d}$, then $\boldsymbol{X}_{\boldsymbol{t}}$ and $\boldsymbol{Y}_{\boldsymbol{t}}$ are said to be cointegrated of order $\boldsymbol{d}, \boldsymbol{b}$, denoted $\boldsymbol{C I}(\boldsymbol{d}, \boldsymbol{b})$. Whilst a number of methodologies for detecting the presence of cointegration have been proposed in the literature of market integration, this study carries out VAR-based cointegration analyses using the methodology developed in Johansen (1988, 1991, and 1995).

Basically, Johansen's cointegration analysis is based on maximum likelihood estimation. He starts with a VAR (k) specification for the $n \times 1$ vector of $I(1)$ variables, $y_{t}$ :

where $\varepsilon_{t} \sim$ i.i.d. $\left(0, \sigma^{2}\right)$

$$
y_{t}=A_{1} y_{t-1}+A_{2} y_{t-2}+\ldots \ldots \ldots . .+A_{k} y_{t-k}+\varepsilon_{t}
$$

Next, defining $\Delta \equiv 1-L$ where $L$ is the lag operator, Johansen rewrites equation (1) as follows: 
$\Delta y_{t}=\alpha+\Gamma_{1} \Delta y_{t-1}+$
where $\Gamma_{i}=-\left(I-A_{1}-\ldots . .-A_{i}\right), i=1, \ldots \ldots . ., k-1$
$\Pi=-\left(I-A_{1}-\ldots . .-A_{k}\right), \mathrm{I}=$ identity vector

$+\Gamma_{k-1} \Delta y_{t-k+1}+\Pi y_{t-k}+v_{t}$

Johansen (1991) suggests two statistics to test the rank of the long-run information matrix $\prod$ :

$$
\begin{gathered}
\lambda_{\text {trace }}(r)=-T \sum_{i=r+1}^{n} \ln \left(1-\hat{\lambda}_{i}\right) \\
\lambda_{\text {max. }}(r, r+1)=-T \ln \left(1-\hat{\lambda}_{r+1}\right)
\end{gathered}
$$

where $\lambda_{i}$ are estimated eigenvalues ranked from largest to smallest. $\lambda_{\text {trace }}$ is called the Trace statistic, which is a likelihood ratio test statistic for the hypothesis that there are at most $r$ cointegrating vectors. The second statistic $\lambda_{\max }$, the Max statistic, tests the hypothesis of $r$ cointegrating vectors against the hypothesis of $r+1$ cointegrating vectors. If the computed values of the statistics are less than the corresponding critical values, then the null hypothesis cannot be rejected.

A salient property of cointegration analysis is its linkage with the error correction representation. Engle and Granger (1987) maintain that the existence of a cointegrating relationship implies that the data are generated according to a partial adjustment or error-correction mechanism. The equilibrium error ensures that, after shortrun deviations from the equilibrium, the system will return to its long-run equilibrium. Using the two-variable system as an example, the error correction model (ECM) has the following format:

$$
\begin{aligned}
& \Delta x_{t}=\alpha_{10}+b_{1}\left(y_{t-1}-\beta x_{t-1}\right)+\sum \alpha_{11}(i) \Delta x_{t-i}+\sum \alpha_{12}(i) \Delta x_{t-i}+\varepsilon_{1 t} \\
& \Delta y_{t}=\alpha_{20}+b_{2}\left(y_{t-1}-\beta x_{t-1}\right)+\sum \alpha_{21}(i) \Delta x_{t-i}+\sum \alpha_{22}(i) \Delta x_{t-i}+\varepsilon_{2 t}
\end{aligned}
$$

where $\varepsilon_{i t}$ are white noise disturbance terms and $\left(y_{t-1}-\beta x_{t-1}\right)$ is the error correction term, which measures last period's equilibrium error. The coefficients associated with the error correction terms can be interpreted as the speed of adjustment since they represent the responses of the variables to the deviations from equilibrium. If a simple but common case when $x_{t}$ and $y_{t}$ are I(1), all terms with $\Delta x_{t}$ and $\Delta y_{t}$ in expressions (5) and (6) are stationary. Therefore, $\left(y_{t-1}-\beta x_{t-1}\right)$ must also be stationary, implying that $x_{t}$ and $y_{t}$ are cointegrated.

\subsection{Granger's Causality Analysis}

Granger's approach $(1969,1988)$ to the question of whether $\boldsymbol{X}$ causes $\boldsymbol{Y}$ is to see how much of the current $\boldsymbol{Y}$ can be explained by past values of $\boldsymbol{Y}$ and then to see whether adding lagged values of $\boldsymbol{X}$ can improve the explanation. In other words, $\boldsymbol{Y}$ is said to be Granger-caused by $\boldsymbol{X}$ if $\boldsymbol{X}$ helps in the prediction of $\boldsymbol{Y}$, or equivalently, if the coefficients on the lagged $\boldsymbol{X}$ 's are statistically significant.

As recommended by Sims et al. (1990) and Enders (1995), the nonstationarity and cointegration tests should be first carried out prior to conducting the Granger's causality tests, in order to see to it that the Granger causality results will not generate nonsense inferences. Hence, based upon the results of both the nonstationarity and cointegration tests, the existence of three different cases is envisioned as follows:

- If the time series are found to be stationary or $I(0)$ to begin with, the Granger's causality tests will be based on the following bivariate vector autoregressive (VAR) equations:

$$
\begin{gathered}
X_{t}=\alpha_{\chi}+\sum_{i=1}^{k} \beta_{\chi, i} X_{t-i}+\sum_{i=1}^{k} \gamma_{\chi, i} Y_{t-i}+\varepsilon_{\chi, t} \\
Y_{t}=\alpha_{y}+\sum_{i=1}^{k} \beta_{y, i} Y_{t-i}+\sum_{i=1}^{k} \gamma_{y, i} X_{t-i}+\varepsilon_{y, t}
\end{gathered}
$$

where $X_{t}$ represents a sector index at time $t, Y_{t}$ is another sector index at time $t, \alpha_{\chi}$ and $\alpha_{y}$ are the intercept terms, $\boldsymbol{E}_{\chi, t}$ and $\boldsymbol{E}_{y, t}$ are the stochastic error terms assumed to be serially uncorrelated with zero mean and 
finite covariance matrix. $K$ is the lag length, $\beta_{\chi, i}$ is the parameter of the past value of $X$, which indicates how much past value of $X$ explains the current value of $X$, and $\gamma_{\chi}, i$ is the parameter of the past value of $Y$, which shows how much past value of $Y$ explains the current value of $X$. Similar notations apply for $\beta_{y, i}$ and $\boldsymbol{\gamma}_{y, i}$ in equation (8).

- If the time series are nonstationary or $I(1)$ and not cointegrated, they will be converted to an $I(0)$ by taking the first difference, and the following Granger's causality tests can be applied:

$$
\begin{gathered}
\Delta X_{t}=\alpha_{\chi}+\sum_{i=1}^{k} \beta_{\chi, i} \Delta X_{t-i}+\sum_{i=1}^{k} \gamma_{\chi, i} \Delta Y_{t-i}+\varepsilon_{\chi, t} \\
\Delta Y_{t}=\alpha_{y}+\sum_{i=1}^{k} \beta_{y, i} \Delta Y_{t-i}+\sum_{i=1}^{k} \gamma_{y, i} \Delta X_{t-i}+\varepsilon_{y, t}
\end{gathered}
$$

There exits also the possibility that the time series of a variable is found to be $I(0)$ and the other $I(1)$. In this case, the $I(1)$ variable will be included in the equation in terms of first differences whereas the $I(0)$ variable will be included in levels. As the first differences of an $I(1)$ series will be converted to $I(0)$, this procedure ensures that all series included in the equation are $I(0)$ (Sander \& Kleimeier, 2003).

- Lastly, if the time series are found to be $I(1)$ and cointegrated, a VAR estimation in first differences will be misleading. Engle and Granger (1987) and Granger (1988) suggest that, in the presence of cointegration, the causality tests in (9) and (10) be augmented with a lagged error correction term (ECT), derived from the cointegrating relationship, and estimated within a vector error correction model (VECM). This procedure helps to avoid the misspecification of the VAR model. In this case, the following causality test can be applied:

$$
\begin{gathered}
\Delta X_{t}=\alpha_{\chi}+\sum_{i=1}^{k} \beta_{\chi, i} \Delta X_{t-i}+\sum_{i=1}^{k} \gamma_{\chi, i} \Delta Y_{t-i}+\varphi_{\chi} E C T_{\chi, t-i}+\varepsilon_{\chi, t} \\
\Delta Y_{t}=\alpha_{y}+\sum_{i=1}^{k} \beta_{y, i} \Delta Y_{t-i}+\sum_{i=1}^{k} \gamma_{y, i} \Delta X_{t-i}+\varphi_{y} E C T_{y, t-i}+\varepsilon_{y, t}
\end{gathered}
$$

where $\varphi_{x}$ and $\varphi_{y}$ are the parameters of the ECT, gauging the error correction mechanism that drives the $X_{t}$ and $\boldsymbol{Y}_{t}$ back to their long-run equilibrium relationship.

Siklos and Ng (2001) point out that much as cointegration analysis shows the presence or absence of Granger causality, it does not indicate the direction of causality between variables under study. This direction of Granger causality can be detected through the VECM. Also, the VECM approach permits the distinction between causality based on short-run dynamics of VAR and on the disequilibrium adjustment of the ECT.

Finally, because the outcomes of Granger's causality analysis are very sensitive to the number of lags included in the regression, the Akaike Information Criterion (AIC) is used in order to determine the appropriate number of lags.

\section{Data and Summary Statistics}

\subsection{Sample Data}

To address the issues of interest, the empirical analysis relies on daily stock index closing prices for the individual market sectors. The data series are obtained from the EGX database. The investigation period extends from 3 April 2011 to 31 May 2015. After excluding non-trading days, the sample size for each index comes to 1015 daily observations. The EGX accommodates 17 equity sectors representing a diverse universe of sectors. The empirical analysis, however, concentrates on the top 8 most actively traded sectors that, by the end of the sample period, form together as much as $86.75 \%$ of the total market capitalisation. These sectors are banks (BNK, henceforth), chemicals (CHM, henceforth), construction and materials (CML, henceforth), financial services excluding banks (FSX, henceforth), food and beverages (FBV, henceforth), industrial goods and services and automobiles (IGSA, henceforth), real estate (RET, henceforth) and telecommunications (TLE, henceforth). The daily return, $R_{t, i}$, for each sector index is computed as the first difference of natural logarithm of stock price indices $(\ln \mathrm{p})$ as follows:-

$$
R_{t, i}=\ln \left(P_{t, i}\right)-\ln \left(P_{t-1, i}\right)
$$

where $P_{t, i}$ denotes the closing sector price index $i$ on day $t$.

Indeed, the use of higher frequency data (i.e., daily data) is preferable to the use of lower frequency data (i.e., 
weekly, monthly, or quarterly data) due to the fact that longer time horizons are less capable of capturing rapid transmission of information amongst the different market sectors in the short run and can blank out transient interactions which may last only a few days (Cotter, 2004; Narayan et al., 2004).

\subsection{Univariate Characteristics}

It is appropriate at this stage to provide some perspective on the properties and trends of the individual sector indices of the EGX. The summary statistics of the daily stock index returns presented in Table 1 spotlight a number of conspicuous findings.

Table 1. Descriptive statistics of daily sector index returns

\begin{tabular}{ccccccccc}
\hline & BNK & CHM & CML & FBV & FSX & IGSA & RET & TLE \\
\hline Mean & 0.085 & -0.017 & 0.016 & 0.051 & -0.013 & -0.011 & 0.066 & -0.008 \\
Maximum & 9.161 & 9.312 & 8.415 & 9.453 & 8.647 & 8.390 & 9.504 & 8.949 \\
Minimum & -10.220 & -10.665 & -9.952 & -10.203 & -9.643 & -8.351 & -10.247 & -9.804 \\
Std. Dev. & 2.749 & 1.385 & 1.578 & 1.671 & 1.866 & 1.535 & 2.157 & 1.789 \\
C.V. & 32.341 & -81.470 & 98.625 & 32.765 & -143.538 & 139.545 & 32.682 & -223.625 \\
Skewness & 0.036 & -0.562 & -0.177 & 0.076 & -0.207 & -0.064 & -0.132 & 0.142 \\
Kurtosis & 6.709 & 13.553 & 7.071 & 6.948 & 5.702 & 7.269 & 4.939 & 6.354 \\
J-B Test & $582.055^{*}$ & $4763.49^{*}$ & $706.298^{*}$ & $660.329^{*}$ & $315.997 *$ & $771.621^{*}$ & $162.089^{*}$ & $479.381^{*}$ \\
\hline
\end{tabular}

Notes. This table reports some univariate characteristics of daily index returns. The sector indices include Banks (BNK), Chemicals (CHM), Construction and Materials (CML), Food and Beverage (FBV), Financial Services excluding Banks (FSX), Industrial Goods and Services and Automobiles (IGSA), Real Estate (RET), and Telecommunications (TLE). Std Dev. is the standard deviation, an absolute measure for risk. C.V. is the coefficient of variation, a relative measure for risk. J-B is the Jarque-Bera test for normality. Both mean and standard deviation are in percentage terms. The sample size for each index is 1015 daily observations. * denotes the $1 \%$ significance level.

First, BNK sector outperforms the other sectors in terms of average daily index returns (0.085) over the entire sample period, but it also experiences the highest level of return volatility measured by the standard deviation (2.749). Second, sectors of CHM, FSX, IGSA, and TLE appear to perform the worst during the sample period with negative daily return averages of (0.017) and (0.013), (0.011), and (0.008), respectively, probably reflecting the downturn in the market activities of these sectors due to the adverse consequences of the January 2011 uprising. Third, minimum levels of daily index returns bear a negative sign with no exception in the sectors analyzed. Fourth, on a risk/return basis, the sectors that offer the lowest, and hence most beneficial, Coefficient of Variation (CV) include BNK (32.341), RET (32.682), and FBV (32.765). Fourth, daily returns are positively skewed for BNK, FBV, and TLE sectors, implying that the return distributions of these series around the mean have a long right tail (extreme gain), but negatively so for the remaining indices, suggesting that the distributions of these series around the mean have a long left tail (extreme loss). Lastly, the kurtosis statistic for each time series is considerably greater than three, indicating that the distributions of the underlying sector index returns are leptokurtic (i.e., peaked around the mean), relative to the Gaussian distribution. This finding is corroborated by the relevant Jarque-Bera test that presents clear evidence to reject the null hypothesis of normality for the distributions of all sectors at $1 \%$ significance level.

Closely related to this stage of preliminary analyses is the examination of cross-sector contemporaneous correlation coefficients over the sample period. A perusal of Table 2 unveils some noteworthy points.

Table 2. Cross-sector correlation coefficients based on daily index returns

\begin{tabular}{|c|c|c|c|c|c|c|c|c|}
\hline & BNK & СНM & CML & FBV & FSX & IGSA & RET & TLE \\
\hline BNK & 1 & & & & & & & \\
\hline CHM & $\begin{array}{c}0.582 * \\
(22.759)\end{array}$ & 1 & & & & & & \\
\hline CML & $\begin{array}{c}0.607 * \\
(24.316)\end{array}$ & $\begin{array}{c}0.552^{*} \\
(21.066)\end{array}$ & 1 & & & & & \\
\hline FBV & $\begin{array}{c}0.556^{*} \\
(21.320)\end{array}$ & $\begin{array}{c}0.521 * \\
(19.444)\end{array}$ & $\begin{array}{c}0.492 * \\
(17.966)\end{array}$ & 1 & & & & \\
\hline FSX & $\begin{array}{c}0.705^{*} \\
(31.617)\end{array}$ & $\begin{array}{c}0.655^{*} \\
(27.588)\end{array}$ & $\begin{array}{c}0.655^{*} \\
(27.575)\end{array}$ & $\begin{array}{c}0.594 * \\
(23.542)\end{array}$ & 1 & & & \\
\hline
\end{tabular}




\begin{tabular}{ccccccccc}
\hline \multirow{2}{*}{ IGSA } & $0.634^{*}$ & $0.599^{*}$ & $0.581^{*}$ & $0.586^{*}$ & $0.745^{*}$ & 1 & & \\
& $(26.101)$ & $(23.819)$ & $(22.712)$ & $(23.059)$ & $(35.513)$ & & & \\
\multirow{2}{*}{ RET } & $0.712^{*}$ & $0.664^{*}$ & $0.655^{*}$ & $0.616^{*}$ & $0.857^{*}$ & $0.739^{*}$ & & \\
& $(32.287)$ & $(28.335)$ & $(27.615)$ & $(24.903)$ & $(52.837)$ & $(34.926)$ & & \\
\multirow{2}{*}{ TLE } & $0.629^{*}$ & $0.576^{*}$ & $0.595^{*}$ & $0.549 *$ & $0.712^{*}$ & $0.633^{*}$ & $0.722^{*}$ & 1 \\
& $(25.805)$ & $(22.405)$ & $(23.590)$ & $(20.930)$ & $(32.276)$ & $(26.045)$ & $(33.232)$ & 1 \\
\hline
\end{tabular}

Note. This table shows the pairwise correlation coefficients between the daily stock index returns of the corresponding sectors. These sectors are Banks (BNK), Chemicals (CHM), Construction and Materials (CML), Food and Beverage (FBV), Financial Services excluding Banks (FSX), Industrial Goods and Services and Automobiles (IGSA), Real Estate (RET), and Telecommunications (TLE). * denotes the 1\% significance level. The $t$ statistics are enclosed in parentheses.

First, all pairwise contemporaneous correlations are positive and statistically significant at the $1 \%$ level, suggesting that sectors of the EGX tend to respond consistently to the market forces and to the arrival of new relevant information. Second, all pairwise correlations seem to be relatively high during the sample period, with the correlation of CML and FBV sectors being the lowest (0.492) and the correlation of FSX and RET being the highest (0.857). This result is, however, not surprising largely because of the thinness of the EGX. Third and last, FBV sector seems to be the least correlated with the other sectors, as indicated by its pairwise correlations that range between 0.492 and 0.616 , whereas RET sector appears to be the most correlated with the other sectors, as shown by its pairwise correlations that range between 0.616 and 0.857 .
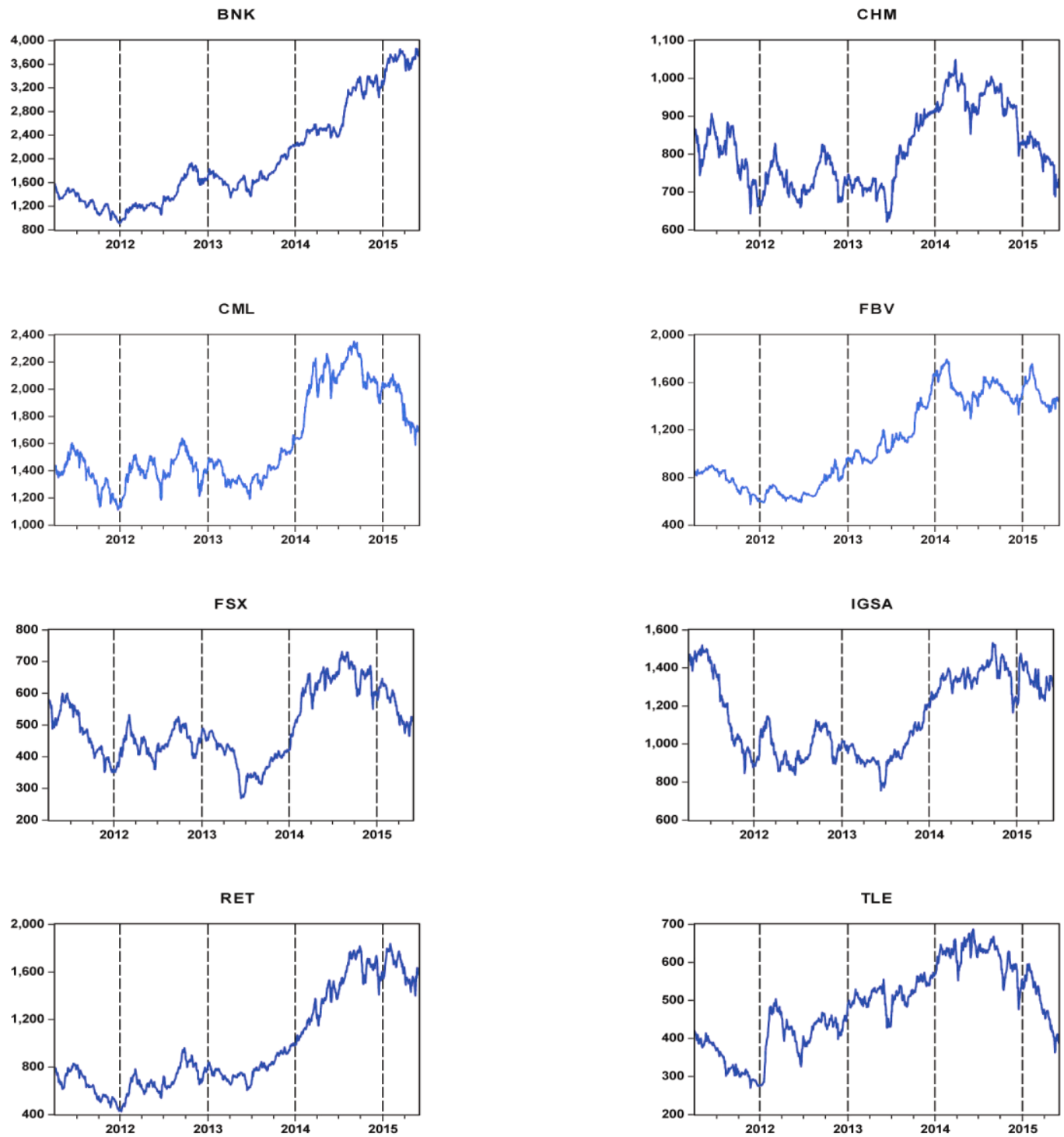

Figure 1. The time evolution of the sample sector indices over the investigation period 
To end off this section, Figure 1 presents trend plots of the individual sector price indices. Based on the visual observation, it is clear that all equity market sectors, with the exception of BNK sector, experience a large up-and-down swing during the sample period. More interesting, the conspicuous downturn trend in all sector indices seems to break out in 2012-2013, coincident with the repercussions of the Egyptian uprising that overshadowed the economic and financial climate. Additionally, Figure 1 suggests that all of the individual time series under study seem to be nonstationary stochastic processes.

\section{Empirical Findings}

\subsection{Results of Unit Root Tests}

As a starting point, the order of integration of each variable is explored using the ADF, the PP, and the KPSS unit root tests. It is worth noting that both the ADF and PP regression equations include an intercept and a linear trend. Furthermore, the KPSS test is performed with both an intercept and a time trend since all sector indices in Figure 1 clearly display trend-like behaviour, not to mention the other option (i.e., including only a constant in the KPSS test regression) is merely a special case of this more general specification.

The results of the unit root tests are presented in Table 3. Since the test statistics of the ADF and PP tests are higher than the critical value (i.e., -3.967), the null hypothesis that the individual sector price indices contain a unit root in the log forms can not be rejected at $1 \%$ significance level. However, there is no evidence to support the existence of a unit root in log first differences of the individual sector price indices. Furthermore, the KPSS test results indicate that the null hypothesis that each sector price index is a stationary process in the log forms is rejected at $1 \%$ significance level, since the test statistics exceed the critical value (i.e., 0.216). However, the KPSS test fails to reject the null hypothesis when the individual time series are in their log first differences.

Table 3. Results of unit root tests

\begin{tabular}{ccccccc}
\hline & \multicolumn{3}{c}{ Log Levels } & \multicolumn{3}{c}{ Log First Differences } \\
\cline { 2 - 7 } Industry index & ADF & PP & KPSS & ADF & PP & KPSS \\
\hline BNK & -2.372 & -2.395 & $0.800^{*}$ & $-29.463^{*}$ & $-29.492^{*}$ & 0.047 \\
CHM & -2.001 & -1.971 & $0.413^{*}$ & $-28.893^{*}$ & $-28.808^{*}$ & 0.117 \\
CML & -1.791 & -1.704 & $0.438^{*}$ & $-28.816^{*}$ & $-28.739^{*}$ & 0.121 \\
FBV & -1.979 & -2.075 & $0.429^{*}$ & $-29.072^{*}$ & $-29.196^{*}$ & 0.125 \\
FSX & -2.204 & -2.197 & $0.501^{*}$ & $-25.321^{*}$ & $-25.275^{*}$ & 0.102 \\
IGSA & -2.388 & -2.408 & $0.666^{*}$ & $-26.332^{*}$ & $-26.279^{*}$ & 0.091 \\
RET & -2.610 & -2.575 & $0.721^{*}$ & $-25.384^{*}$ & $-25.301^{*}$ & 0.067 \\
TLE & -1.207 & -1.172 & $0.391^{*}$ & $-26.182^{*}$ & $-26.183^{*}$ & 0.119 \\
\hline
\end{tabular}

Notes. This table reports the results of unit root tests. The sector indices include Banks (BNK), Chemicals (CHM), Construction and Materials (CML), Food and Beverage (FBV), Financial Services excluding Banks (FSX), Industrial Goods and Services and Automobiles (IGSA), Real Estate (RET), and Telecommunications (TLE). ADF, PP, and KPSS denote the Augmented Dickey-Fuller test, Phillips-Perron test, and the Kwiatkowski, Phillips, Schmidt, and Shin test for unit roots, respectively. For either ADF or PP test, the critical value, with both an intercept and a trend, is -3.967 at the $1 \%$ level of significance. For the KPSS test, the critical value is 0.216 at the $1 \%$ level of significance. The critical values are obtained from MacKinnon (1996) for the ADF and PP test statistics and from Kwiatkowski et al. (1992) for the KPSS test statistics. * denotes rejection of the corresponding null hypothesis at the $1 \%$ level of significance.

These findings are broadly consistent with those evidenced by most market integration studies (e.g., Kanas, 1998; Ghosh et al., 1999; Siklos et al., 2001; Loo et al., 2015), which demonstrate that capital market index series become stationary after differencing once. Accordingly, since unit root tests establish that all sector index levels are individually integrated of order one $(I(1))$, the cointegration analysis is carried out with these indices because they are all integrated of the same order as required for cointegration.

\subsection{Results of Johansen's Cointegration Analysis}

To begin with, before Johansen's multivariate cointegration analysis can be carried out, the optimal number of lags in the VAR system should be determined. On the basis of the Akaike Information Criterion (AIC), a lag length of four is identified. The chosen lag length is sufficient to remove any serial correlation in the residuals of the VAR. The results of the Johansen's cointegration analysis are shown in Table 4. 
Table 4. Results of Johansen's multivariate cointegration tests

\begin{tabular}{ccccccc}
\hline Hypothesized & \multicolumn{3}{c}{$\lambda$ Trace } & \multicolumn{3}{c}{$\lambda$ Max } \\
\cline { 2 - 7 } No. of CE(s) & Statistic & Critical Value & Prob.** & Statistic & Critical Value & Prob.** \\
\hline None * & 173.837 & 159.529 & 0.006 & 67.907 & 52.363 & 0.001 \\
At most 1 & 105.930 & 125.615 & 0.415 & 31.601 & 46.231 & 0.683 \\
At most 2 & 74.328 & 95.754 & 0.568 & 26.199 & 40.077 & 0.688 \\
At most 3 & 48.129 & 69.819 & 0.717 & 21.169 & 33.876 & 0.671 \\
At most 4 & 26.959 & 47.856 & 0.855 & 11.982 & 27.584 & 0.933 \\
At most 5 & 14.977 & 29.797 & 0.782 & 8.557 & 21.132 & 0.866 \\
At most 6 & 6.419 & 15.494 & 0.645 & 5.599 & 14.264 & 0.665 \\
At most 7 & 0.820 & 3.841 & 0.365 & 0.820 & 3.841 & 0.365 \\
\hline
\end{tabular}

Notes. This table shows the results of Johansen's multivariate cointegration test. CE(s) means number of cointegrating equations. According to the Akaike Information Criterion (AIC), four lags are employed in the cointegration analysis. * denotes rejection of the null hypothesis at the 5\% level of significance. ** MacKinon-Haug-Michelis (1999) $p$-values. The sector indices include Banks (BNK), Chemicals (CHM), Construction and Materials (CML), Food and Beverage (FBV), Financial Services excluding Banks (FSX), Industrial Goods and Services and Automobiles (IGSA), Real Estate (RET), and Telecommunications (TLE).

As reported in Table 4, when $\boldsymbol{r}=0$ the computed values of the Trace statistic and Max eigenvalue statistic (173.837 and 67.907, respectively) exceed the corresponding 5\% critical values (159.529 and 52.363, respectively), indicating that at least one significant cointegrating vector exists for all the sector indices under scrutiny. For more than one cointegrating vector, however, the computed values of the Trace statistic and Max eigenvalue statistic (105.930 and 31.601, respectively) are found to be lower than the corresponding 5\% critical values (125.615 and 46.231, respectively), providing evidence of the existence of only a single cointegrating vector within the eight sector indices over the sample period. Consequently, these results lend weight to the rejection of the null hypothesis of no cointegration at the 5\% significance level, implying that these sector indices are tightly linked together at least in the long run.

The findings of cointegration analysis are broadly consistent with the economic intuition that the capital market sectors within a certain economy share to a lesser or greater extent a long-run equilibrium relationship. That is, they have a tendency to move towards the same direction, at least in the long run.

Accordingly, two salient implications are worthy of mention. First, the different sectors of the EGX are more or less influenced by the economy's fundamentals (e.g., inflation rates, real interest rates, monetary policy, and productivity) that bring them together in the long run. Although there is still room to derive benefits from portfolio diversification in the short run, it is not possible in the long run because the presence of common factors amongst the market sectors circumscribes the amount of independent variation. Thus, the benefits from diversifying investments into the eight sectors would dwindle away. Second, there must be some significant Granger's causality in the system at least in one direction. This direction can be tracked down through a VECM derived from the long-run cointegrating vector.

\subsection{Results of Granger's Causality Analysis}

As indicated in section 4.3, in case of the presence or absence of a long-run equilibrium relationship, the possibility of a short-run relationship between the variables under scrutiny may still exist. To test for this possibility, the Granger's causality analysis is employed.

However, since Johansen's multivariate cointegration analysis unveils a single cointegrating vector within the eight capital market sector indices, a VEC Granger causality/Block Exogeneity Wald test is in place. This test assesses whether the inclusion of lagged values of a variable is important for explaining the dynamics of the other variables in the system of equations in addition to the explanatory power of the lags of those other variables. In other words, Block exogeneity Wald test indicates whether lagged values of independent variable(s) jointly affect a particular dependent variable. Hence, a necessary condition for the exogeneity of $\boldsymbol{Y}$ is that current and past values of $\boldsymbol{X}$ do not affect $\boldsymbol{Y}$ (Enders, 1995). An optimal lag length of five is chosen, based on the AIC selection criteria.

Summary results of the Granger causality/Block Exogeneity Wald test are displayed in Table 5. Each entry in the Table denotes the Wald $\chi^{2}$ Statistics of the sector index on the left-hand side Granger-caused by the sector index at the top.

A perusal of Table 5 reveals some important findings. First, in 40 bivariate cases out of a total of 56 , there exist 
independence relationships between each pair of the sector indices of the EGX. Second, only 3 significant bidirectional causality are detected between (CML \& CHM), (FSX \& CML), and (FSX \& RET), implying that the information content of lagged price changes of either sector index in each pair can be used to predict current price changes of the other sector in the short run. Third, for the remaining cases, the test results suggest the presence of unidirectional causality relationships throughout the sample period considered. Thus, in most bivariate cases, the null hypothesis of no pairwise causal relationship cannot be rejected at the conventional levels of significance.

The results shown in Table 5 also suggest that sectors IGSA and TLE appear to exert no significant influence on stock price movements of the other sectors, reflecting their relatively small size and modest market capitalization. On the other hand, the dominant sectors are found to be BNK and CML, with each Granger-causing 5 and 4 other sector indices, respectively. Finally, in terms of econometric exogeneity, sectors of BNK and FBV appear to be statistically exogenous to changes in other sectors of the market.

Taken together, the findings suggest that the short-term causal relationships between the sectors of the EGX are considerably limited and, where they exist, almost unidirectional. These findings may sound typical, especially given that the EGX is in effect inefficient because trading is comparatively thin for the information to be disseminated timely and broadly. The implication of these observations is that an attempt to predict the stock price movements of a sector index based on the information content of the lagged values of another sector index in the EGX is expected to be futile in most cases.

Table 5. Results of Granger Causality/Block Exogeneity Wald test

\begin{tabular}{|c|c|c|c|c|c|c|c|c|}
\hline & \multicolumn{7}{|c|}{ Short-run lagged differences } & \multirow[b]{2}{*}{$\triangle \mathbf{T L E}$} \\
\hline & $\triangle \mathbf{B N K}$ & $\Delta \mathrm{CHM}$ & $\Delta \mathrm{CML}$ & $\Delta$ FBV & $\Delta \mathbf{F S X}$ & $\triangle$ IGSA & $\Delta \mathbf{R E T}$ & \\
\hline Dependent Variable & \multicolumn{8}{|c|}{ Wald $\chi^{2}$ Statistics } \\
\hline$\Delta \mathbf{B N K}$ & - & 8.334 & 6.595 & 8.873 & 2.307 & 1.002 & 18.191 & 9.239 \\
\hline$\Delta$ CHM & $7.858^{* *}$ & - & $9.819 * *$ & $8.921 * *$ & 8.812 & 8.720 & 4.015 & 6.866 \\
\hline$\Delta \mathbf{C M L}$ & $3.487^{* *}$ & $13.869^{* * *}$ & - & $11.514 * *$ & $9.439 * *$ & 2.272 & 7.664 & 1.253 \\
\hline$\triangle \mathbf{F B V}$ & 5.404 & 3.648 & 2.786 & - & 3.743 & 4.842 & 6.833 & 9.048 \\
\hline$\Delta \mathbf{F S X}$ & 6.121 & 7.073 & $23.090 * * *$ & 2.482 & - & 6.085 & $20.539 * *$ & 4.947 \\
\hline$\Delta$ IGSA & $4.377 * *$ & 5.309 & $11.973 * *$ & $10.943^{* *}$ & 7.887 & - & 7.808 & 2.868 \\
\hline$\Delta$ RET & $8.433 * * *$ & 7.518 & $18.522 * *$ & 5.422 & $13.786^{* * *}$ & 3.541 & - & 4.479 \\
\hline$\triangle$ TLE & $2.739 *$ & 2.108 & 5.652 & 6.626 & 4.279 & 6.293 & 6.011 & - \\
\hline
\end{tabular}

Notes. This table displays the results obtained from the Granger Causality/Block Exogeneity Wald test. The sector indices include Banks (BNK), Chemicals (CHM), Construction and Materials (CML), Food and Beverage (FBV), Financial Services excluding Banks (FSX), Industrial Goods and Services and Automobiles (IGSA), Real Estate (RET), and Telecommunications (TLE). $\Delta$ is the first difference operator. Each entry in the table denotes the Wald $\chi^{2}$ Statistics of the sector index on the left-hand side Granger-caused by the sector index at the top. Based on the Akaike Information Criterion (AIC), a lag length of five is employed. ***, **, and * denote rejection of the null hypothesis (no Granger causality) at the $1 \%, 5 \%$, and $10 \%$ level of significance, respectively.

\section{Summary and Conclusions}

A full understanding of the degree to which market sector indices within an economy move together is of paramount importance to portfolio managers seeking to allocate or rebalance their investments effectively. It is well documented that investment portfolios based on economic sectors that are relatively independent are more likely to add value and increase the opportunity to eliminate a fundamental part of investment risk.

Contributing to the meagre published literature on interrelationships amongst stock market sectors within a single economy, this study makes the first attempt to provide empirical analyses about the long-run equilibrium relationships as well as the short-run causal linkages amongst the various sectors of the EGX.

The results of Johansen's multivariate cointegration analysis provide evidence of the existence of only a single cointegrating vector within the eight sector market indices over the sample period. These results are broadly consistent with the economic intuition that the capital market sectors within a certain economy have a tendency to move towards the same direction, at least in the long run.

On the other hand, the results of Granger's causality analysis show that the short-run causal relationships between the economic sectors of the EGX are considerably limited and, where they exist, practically unidirectional. The dominant sectors are BNK and CML, with each Granger-causing 5 and 4 other sector indices, 
respectively. On the other hand, sectors of BNK and FBV appear to be statistically exogenous to changes in other sectors of the market.

These results have a bearing on the potential benefits from diversifying portfolios into the different sectors of the EGX. Although there is still room to derive benefits from portfolio diversification in the short run, it is not possible in the long run because the presence of common factors amongst the capital market sectors circumscribes the amount of independent variation. Thus, the benefits from diversifying investments into the eight sectors would dwindle away.

\section{References}

Antoniou, A., Olusi, O., \& Paudyal, K. (2010). Equity home-bias: A suboptimal choice for UK investors? European Financial Management, 16(3), 449-479. http://dx.doi.org/10.1111/j.1468-036X.2008.00462.x

Arbeláez, H., Urrutia, J., \& Abbas, N. (2001). Short-term and long-term linkages amongst the Colombian capital market indexes. International Review of Financial Analysis, 10(3), 237-273. http://dx.doi.org/10.1016/S1057-5219(01)00051-5

Arouri, M., Hammoudeh, S., Jawadi, F., \& Nguyen, D. K. (2014). Financial linkages between US sector credit default swaps markets. Journal of International Financial Markets, Institutions \& Money, 33(6), 223-243. http://dx.doi.org/10.1016/j.intfin.2014.08.002

Arshanapalli, B., \& Doukas, J. (1993) International stock Market linkages: Evidence from the Pre- and Post-October 1987 Period. Journal of Banking \& Finance, 17(1), 193-208. http://dx.doi.org/10.1016/0378-4266(93)90088-U

AuYong, H. H., Gan, C., \& Treepongkaruna, S. (2004). Cointegration and causality in the Asian and emerging exchange markets: Evidence from the 1990s financial crises. International Review of Financial Analysis, 13(4), 479-515. http://dx.doi.org/10.1016/j.irfa.2004.02.024

Bekaert, G., Harvey, C. R., \& Angela, N. (2005). Market integration and contagion. Journal of Business, 78(1), 39-69. http://dx.doi.org/10.1086/426519

Cavaglia, S., Melas, D., \& Tsouderos, G. (2000). Cross sector and cross country international equity diversification. The Journal of Investing, 9(1), 65-71. http://dx.doi.org/10.3905/joi.2000.319401

Chang, E., Eun, C. S., \& Kolodny, R. (1995). International diversification though closed-end country funds. Journal of Banking \& Finance, 19(7), 1237-1263. http://dx.doi.org/10.1016/0378-4266(94)00122-J

Chung, H. (2005). The contagious effects of the Asian financial crisis: Some evidence from ADR and country $\begin{array}{llll}\text { funds. Journal of Multinational Financial Management, } & \text { 15(1), 67-84. }\end{array}$ http://dx.doi.org/10.1016/j.mulfin.2004.01.001

Chung, P. J., \& Liu, D. J. (1994). Common stochastic trends in Pacific Rim stock markets. The Quarterly Review of Economics and Finance, 34(3), 241-259. http://dx.doi.org/10.1016/1062-9769(94)90026-4

Cotter, J. (2004) International capital market integration in a small open economy: Ireland January 1990-December 2000. International Review of Financial Analysis, 13(5), 669-685. http://dx.doi.org/10.1016/j.irfa.2004.02.018

Crowder, W. (1996). A re-examination of long-run PPP: The case of Canada, the UK and the US. Review of International Economics, 4(1), 64-78. http://dx.doi.org/10.1111/j.1467-9396.1996.tb00084.x

DeJong, D. N., Nankervis, J. C., Nsavin, E., \& Whiteman, C. H. (1992). Integration versus trend stationarity in time series. Econometrica, 60(2), 423-433. http://dx.doi.org/10.2307/2951602

Dickey, D. A., \& Fuller, W. A. (1979). Distribution of the estimators for autoregressive time-series with a unit roots. Journal of the American Statistical Association, 74, 427-431.

Dickey, D. A., \& Fuller, W. A. (1981). Likelihood ratio statistics for autoregressive time series with a unit root. Econometrica, 49(4), 1057-1072. http://dx.doi.org/10.2307/1912517

Enders, W. (1995). Applied Econometric Time Series (1st ed.). New York, NY: John Wiley \& Sons.

Engle, R. F., \& Granger, C. W. J. (1987). Cointegration and error correction: Representation, Estimation and Testing. Econometrica, 55(2), 251-276. http://dx.doi.org/10.2307/1913236

Erb, C. B., Harvey, C. R., \& Viskanta, T. E. (1997). Demographics and international investment. Financial Analysts Journal, 53(4), 14-28. http://dx.doi.org/10.2469/faj.v53.n4.2096 
Errunza, V., Hogan, K., \& Hung, M. W. (1999). Can the gains from international diversification be achieved without trading abroad? Journal of Finance, 54(6), 2075-2107. http://dx.doi.org/10.1111/0022-1082.00182

Ewing, B. T. (2002). The transmission of shocks among S\&P indexes. Applied Financial Economics, 12(4), 285-290. http://dx.doi.org/10.1080/09603100110090172

Ewing, B. T., Forbes, S. M., \& Payne, J. E. (2003). The effects of macroeconomic shocks on sector-specific returns. Applied Economics, 35(2), 201-207. http://dx.doi.org/10.1080/0003684022000018222

Garten, J. (1997). Trouble ahead in emerging markets. Harvard Business Review, 75(3), 38-50.

Ghosh, A., Saidi, R., \& Johnson, H. (1999). Who moves the Asia - pacific stock markets: U. S. or Japan? Empirical evidence based on the theory of Co-integration. Financial Review, 34(1), 59-70. http://dx.doi.org/10.1111/j.1540-6288.1999.tb00450.x

Granger, C. W. J. (1969). Investigating causal relations by econometric models and cross-spectral methods. Econometrica, 37(3), 424-438. http://dx.doi.org/10.2307/1912791

Granger, C. W. J. (1986). Developments in the study of cointegrated economic variables. Oxford Bulletin of Economics and Statistics, 48(3), 213-228. http://dx.doi.org/10.1111/j.1468-0084.1986.mp48003002.x

Granger, C. W. J. (1988). Some recent developments in a concept of causality. Journal of Econometrics, 39(1-2), 199-211. http://dx.doi.org/10.1016/0304-4076(88)90045-0

Grubel, H. G. (1968). Internationally Diversified Portfolio: Welfare gains and capital flows. American Economic Review, 58(1), 1299-1314.

Izquierdo, A. F., \& Lafuente, J. A. (2004). International transmission of stock exchange volatility: Empirical evidence from the Asian crisis. Global Finance Journal, 15(2), 125-137. http://dx.doi.org/10.1016/j.gfj.2004.02.002

Johansen, S. (1988). Statistical analysis of cointegration vectors. Journal of Economic Dynamics and Control, 12(2-3), 231-254. http://dx.doi.org/10.1016/0165-1889(88)90041-3

Johansen, S. (1991). Estimation and hypothesis testing of cointegration vectors in Gaussian vector autoregressive models. Econometrica, 59(6), 1551-1580. http://dx.doi.org/10.2307/2938278

Johansen, S. (1995). Likelihood-based inference in cointegrated vector autoregressive models. Oxford: Oxford University Press. http://dx.doi.org/10.1093/0198774508.001.0001

Kanas, A. (1998). Long-run benefits from international equity diversification: A note on the Canadian evidence. Applied Economics Letters, 5(10), 659-663. http://dx.doi.org/10.1080/135048598354366

Karmakar, M. (2010). Information transmission between small and large stocks in the National Stock Exchange in India: An empirical study. The Quarterly Review of Economics and Finance, 50(1), 110-120. http://dx.doi.org/10.1016/j.qref.2009.09.007

Kwaitkowski, D., Phillips, P. C. B., Schmidt, P., \& Shin, Y. (1992). Testing the null hypothesis of stationarity against the alternative of a unit root: How sure are we that economic time series have a unit root? Journal of Econometrics, 54(1-3), 159-178. http://dx.doi.org/10.1016/0304-4076(92)90104-Y

Lessard, D. R. (1976). World, Country and Sector Factors in Equity Returns: Implications for Risks Reduction through International Diversification. Financial Analysts Journal, 32(1), 32-38. http://dx.doi.org/10.2469/faj.v32.n1.32

Levy, H., \& Sarnat, M. (1970). International diversification of investment portfolios. American Economic Review, 60(4), 668-675.

Longin, F., \& Solnik, B. (1995). Is the correlation in international equity returns constant: 1960-1990? Journal of International Money and Finance, 14(1), 3-26. http://dx.doi.org/10.1016/0261-5606(94)00001-H

Loo, W. K., Anuar, M. A., \& Ramakrishnan, S. (2015). The dynamic linkage among the Asian REITS market. Pacific Rim Property Research Journal, 21(2), 115-126. http://dx.doi.org/10.1080/14445921.2015.1058036

Masih, A. M. M., \& Masih, R. (2002). Propagative causal price transmission among international stock markets: Evidence from the pre- and post-globalization period. Global Finance Journal, 13(1), 63-91. http://dx.doi.org/10.1016/S1044-0283(02)00039-X

Mohamad, S., Hassan, T., \& Sori, Z. M. (2006). Diversification across economic sectors and implication on portfolio investments in Malaysia. International Journal of Economics and Management, 1(1), 155-172. 
Mun, C. K. C. (2005). Contagion and impulse response of international stock markets around the 9-11 terrorist attacks. Global Finance Journal, 16(1), 48-68. http://dx.doi.org/10.1016/j.gfj.2005.05.002

Narayan, P. K., Smyth, R., \& Nandha, M. (2004). Interdependence and dynamic linkages between the emerging stock markets of South Asia. Accounting and Finance, 44(3), 419-439. http://dx.doi.org/10.1111/j.1467-629x.2004.00113.x

Newey, W., \& West, K. (1994). Automatic lag selection in covariance matrix estimation. Review of Economic Studies, 61(4), 631-653. http://dx.doi.org/10.2307/2297912

Odier, P., \& Solnik, B. (1993). Lessons for International Asset Allocation. Financial Analysts Journal, 49(2), 63-77. http://dx.doi.org/10.2469/faj.v49.n2.63

Olienyk, J. P., Schwebach, R. G., \& Zumwalt, J. K. (2002). The impact of financial crises on international diversification. Global Finance Journal, 13(2), 147-161. http://dx.doi.org/10.1016/S1044-0283(02)00050-9

Perron, P. (1988). Trends and random walks in macroeconomic time series: Further evidence from a new approach. Journal of Economic Dynamics and Control, 12(2-3), 297-332. http://dx.doi.org/10.1016/0165-1889(88)90043-7

Phillips, P. C. B. (1987). Time series regressions with a unit root. Econometrica, 55(2), 277-301. http://dx.doi.org/10.2307/1913237

Phillips, P. C. B., \& Perron, P. (1988). Testing for a unit root in time series regression. Biometrika, 75(2), 335-346. http://dx.doi.org/10.1093/biomet/75.2.335

Phylaktis, K., \& Ravazzolo, F. (2005). Stock market linkages in Emerging markets: Implications for international portfolio diversification. Journal of International Financial Markets, Institutions \& Money, 15(2), 91-106. http://dx.doi.org/10.1016/j.intfin.2004.03.001

Schwert, W. (2002). Tests for unit roots: A Monte Carlo investigation. Journal of Business \& Economic Statistics, 20(1), 5-17. http://dx.doi.org/10.1198/073500102753410354

Shamsuddin, A. F. M., \& Kim, J. H. (2003). Integration and interdependence of stock and foreign exchange markets: An Australian perspective. Journal of International Financial Markets, Institutions \& Money, 13(3), 237-254. http://dx.doi.org/10.1016/S1042-4431(02)00046-X

Sheng, H. C., \& Tu, A. (2000). A Study of cointegration and variance decomposition among national equity indices before and during the period of the Asian financial crisis. Journal of Multinational Financial Management, 10(3-4), 345-365. http://dx.doi.org/10.1016/S1042-444X(00).00034-7

Siklos, P., \& Ng, P. (2001). Integration amongst Asia-Pacific and international stock markets: Common stochastic trends and regime shifts. Pacific Economic Review, 6(1), 89-110. http://dx.doi.org/10.1111/1468-0106.00120

Sims, C. A., Stock, J. H., \& Watson, M. W. (1990). Inference in linear time series models with some unit roots. Econometrica, 58(1), 113-144. http://dx.doi.org/10.2307/2938337

Solnik, B. H. (1974). Why not diversify internationally. Financial Analysts Journal, 30(4), 48-54. http://dx.doi.org/10.2469/faj.v30.n4.48

Soydemir, G. (2000). International transmission mechanism of stock market movements: Evidence from $\begin{array}{lllll}\text { emerging capital markets. Journal of Forecasting, 19(3), 149-176. } & \text { of }\end{array}$ http://dx.doi.org/10.1002/(SICI)1099-131X(200004)19:3<149::AID-FOR735>3.0.CO;2-C

Syriopoulos, T. (2004). International portfolio diversification to Central European stock markets. Applied Financial Economics, 14(17), 1253-1268. http://dx.doi.org/10.1080/0960310042000280465

The Egyptian Exchange. (2014). Annual Report.

Vardhan, H., Sinha, P., \& Vij, M. (2015). Behavior of Indian sectoral stock price indices in the post subprime crisis period. Journal of Advances in Management Research, 12(1), 15-29. http://dx.doi.org/10.1108/JAMR-10-2014-0061

Wang, Z., Kutan A., \& Yang, J. (2005). Information flows within and across sectors in Chinese stock markets. The Quarterly Review of Economics and Finance, 45(4-5), 767-780. http://dx.doi.org/10.1016/j.qref.2003.08.001

Yunus, N. (2013). Dynamic interactions among property types: International evidence based on cointegration

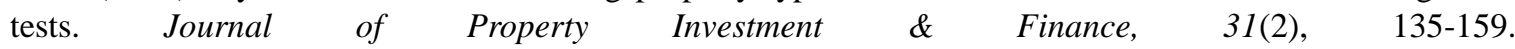


http://dx.doi.org/10.1108/14635781311305372

\section{Copyrights}

Copyright for this article is retained by the author(s), with first publication rights granted to the journal.

This is an open-access article distributed under the terms and conditions of the Creative Commons Attribution license (http://creativecommons.org/licenses/by/3.0/). 